\title{
Comparison of RANS and U-RANS for Flat Plate Film Cooling
}

\author{
Kamil ABDULLAH ${ }^{1, a^{*}}$, Osama H. ABDULGUAD ${ }^{1, b}$, \\ Akmal Nizam MOHAMMED ${ }^{1, \mathrm{c}}$ and Zaid SULEIMAN ${ }^{2, \mathrm{~d}}$
}

${ }^{1}$ Center for Energy and Industrial Environment Studies,

Faculty of Mechanical and Manufacturing Engineering,

Universiti Tun HUssein Onn Malaysia,

Parit Raja, 86400 Johor, MALAYSIA

${ }^{2}$ KAFF Consultancy Sdn. Bhd.,

No. 10-2-2, Medaniaga Siswa Jaya,

Taman Siswa Jaya, Parit Raja

86400 , Johor, MALAYSIA

\begin{abstract}
amkamil@uthm.edu.my, bosama_43@yahoo.com, ‘akmaln@uthm.edu.my, zaid@kaffconsultancy.com
\end{abstract}

Keywords: Flat-Plate Film-cooling, CFD, CFX, RANS, URANS.

\begin{abstract}
Film cooling has been extensively used to provide thermal protection for the external surfaces of gas turbine components. For the past 40 years, numerous number of film cooling hole designs and arrangements have been introduced. Due to broad designs and arrangements of film cooling, numerical investigation has been utilized to provide initial insight on the aerodynamics and thermal performance of the new film cooling designs or arrangements. The present work focuses on the numerical investigation of RANS and URANS analyses on a flat plate film cooling. The investigation aims to provide comparison between various turbulent models available for the Reynolds Average Navier Stokes (RANS) analyses and extended to unsteady Reynolds Average Navier Stokes (URANS). The numerical investigations make used of ANSYS CFX ver. 14 and were carried out at Reynolds Number, $\mathrm{Re}=7,000$ based on the hole diameter at blowing ratio, $\mathrm{BR}=$ 0.5. The results of the RANS analyses show significant influence of the turbulent models on the predicted aerodynamics and thermal performance of the film cooling. The result of URANS indicates limitation of RANS analyses to provide details on the eddied and vortices formation in film cooling flow structure.
\end{abstract}

\section{Introduction}

The modern gas turbine works at the temperature range of $1800 \mathrm{~K}-2000 \mathrm{~K}$ [1], which is higher than the melting temperature of the turbine components materials. Such high operating temperature of the turbine became possible because of application of cooling scheme on the turbine components which includes film cooling. The working concept of film cooling lays on the injection of cold air from the turbine component to provide a thin layer of cool fluid between the hot gases and the blade surface, hence reducing temperature of the surface [3]. The early experimental works of Andreopoulos and Rodi [3] and Fric and Roshko [4] have characterized the evolution and main features of jet in cross flow configurations. The main feature of jet in cross flow is the existent of counter rotating vortex pair which lift the jet away from the surface and hindering the film cooling protection provided by the secondary jet. Numerous number of studies have been undertaken both experimentally and computationally to improve film cooling effectiveness particularly through flow parameters controlling and evolution of film cooling geometries including fan shaped hole [7], sister holes [8], anti vortex cooling hole [9], and shallow angle hole [10]. Given the broad flow parameters and film cooling geometries, numerical investigation has been utilized to provide initial insight on the aerodynamics and thermal performance of the various flow parameters and film cooling geometries. Various numerical schemes of computational fluid dynamics are available in 
the market and it is important for the designers to be provided on the information regarding the capability of these numerical schemes to make available reliable results of their designs. The present work focuses on the numerical investigation of RANS and U-RANS analyses on a flat plate film cooling, aiming to evaluate the capability of different turbulence models to provide accurate prediction of aerodynamics and thermal performance of the film cooling phenomena.

\section{Methodology}

Computational Domain. The present study make used of computational domain which corresponding to the experiments of Pietrzyk [5]. The computational domain consists of film cooling hole inclined at $\theta=35^{\circ}$ toward the main stream direction. The computational domain is laterally restricted to include just half of the cooling hole and one cooling hole for RANS and U-RANS simulations respectively. Details geometry of the computational domain is shown in Figure 1. The present study utilizes hybrid meshes which are constructed through

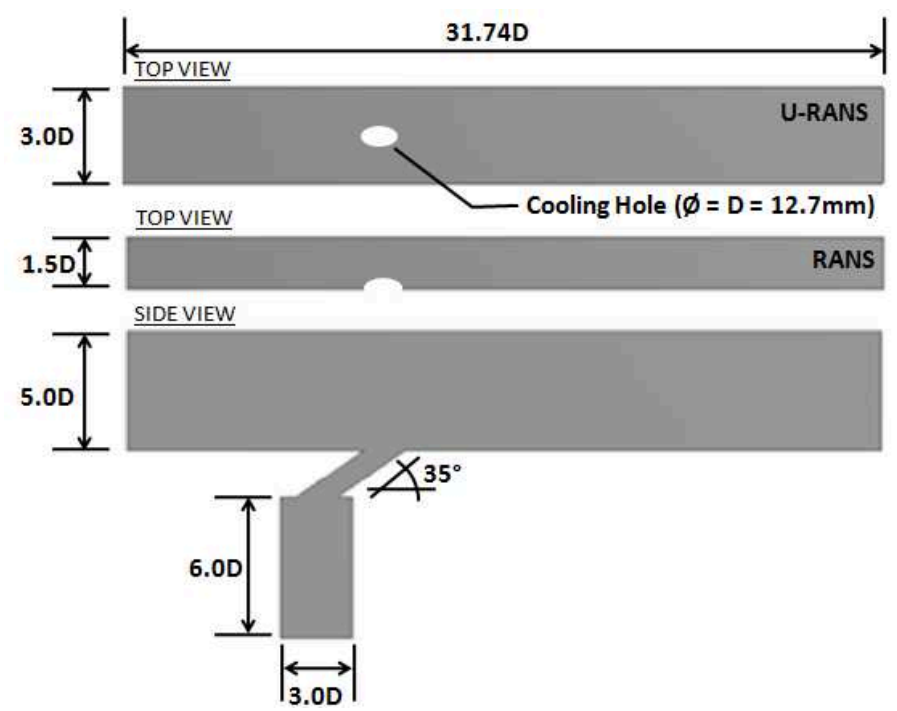

Figure 1: Details on the Computational Domain ANSYS ICEM Meshing software. The near wall regions of the domain occupied with prism layer at $y+$ value less than one to provide better resolution for the simulation. Mesh dependency test was carried out for three different mesh topologies and the final mesh setup used for the present study consists of 10,679,841cells and 21,364,832 cells for RANS and U-RANS analyses respectively.

Numerical Setup. The numerical investigations of the present work are carried out through ANSYS CFX software. The boundary conditions of the simulation correspond to the experimental setup of Pietrzyk [5] as shown in Table 1. Total of five turbulence models are considered for RANS analysis; i) SST, ii) SSG, iii) RNG k- $\varepsilon$, iv) k- $\omega$, and v) standard k- $\varepsilon$ models. The U-RANS model make used of SST turbulence model coupled timedependent solution.
Table 1: Boundary Conditions Details

\begin{tabular}{lc}
\hline Reynolds Number, Re $\mathrm{D}_{\mathrm{D}}$ & $\sim 7000$ \\
\hline Main Flow Mean Velocity $\mathrm{U}_{\infty}$ & $20 \mathrm{~m} / \mathrm{s}$ \\
\hline Blowing Ratio, M & 0.5 \\
\hline Coolant Jet Mean Velocity, $\mathrm{U}_{\mathrm{c}}$ & $10 \mathrm{~m} / \mathrm{s}$ \\
\hline Main Flow Temperature, $\mathrm{T}_{\infty}$ & $303 \mathrm{~K}$ \\
\hline Cooling Jet Temperature, $\mathrm{T}_{\mathrm{c}}$ & $153 \mathrm{~K}$ \\
\hline Density Ratio, DR & 2.0 \\
\hline Time Steps, t * & $1 \mathrm{E}-05$ \\
\hline Convergence Residual & 1E+03 \\
\hline \multicolumn{2}{|c}{ *only applicable for U-RANS }
\end{tabular}




\section{Results and Discussion}

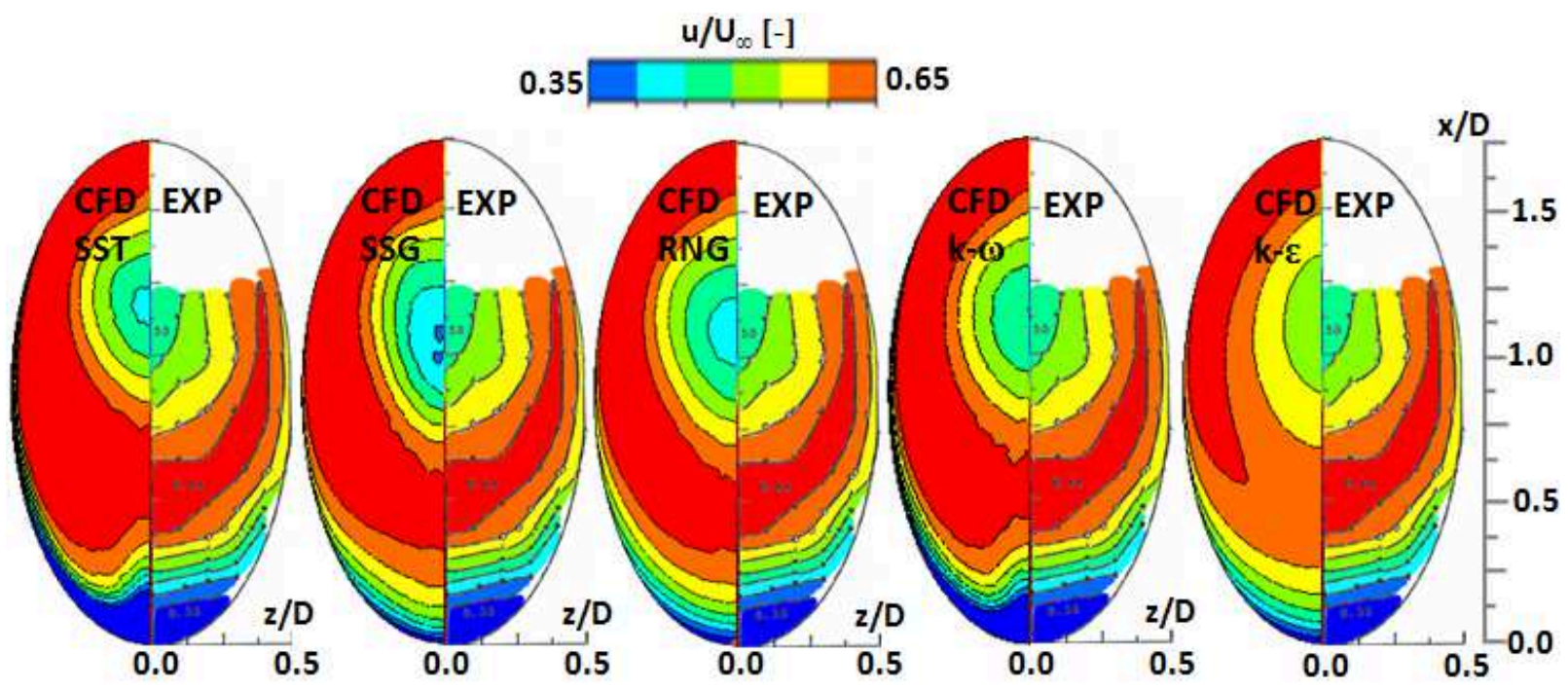

Figure 2: Normalized u-velocity Contour at the Hole Exit Plane for RANS Analyses

Hole Exit Velocity. The cross flow jet evolutions depend largely on the flow structure at the hole exit. The flow structure will determine the characteristics of the shear layer vortices. Figure 2 depicts the comparison between the normalized u-velocity contour at the hole exit predicted by the RANS analyses and the experiments of Pietrzyk [6]. In general, all the turbulence models of RANS producing the same pattern of results with high u-velocity region sandwiched by a low velocity region at the hole center and cooling hole wall. The shear layers of the leeward wall area were observed to be thicker in comparison to the windward wall area. These observations are consequents of the separation region occurrence at the leeward wall during the entering of the secondary air into the cooling hole. The bottom-up direction of the secondary air leads to higher mass concentration at the windward wall area. Although the general characteristics flow structures have been captured by all the considered turbulence models, the results of $-\varepsilon$ model had the highest discrepancy while the others producing satisfactory results in comparison with the experiment.
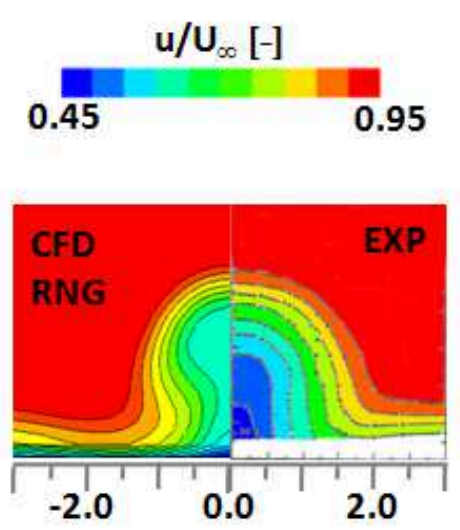
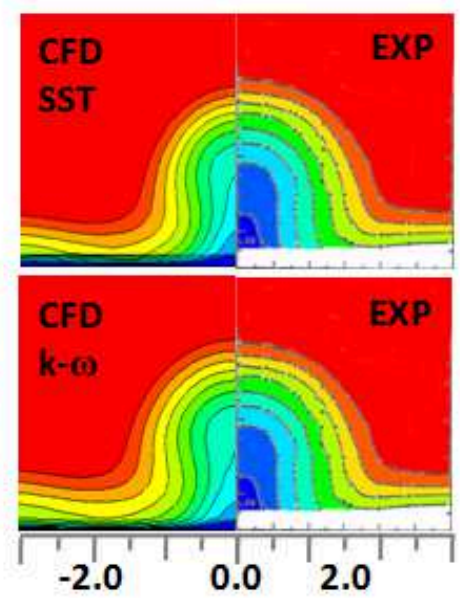

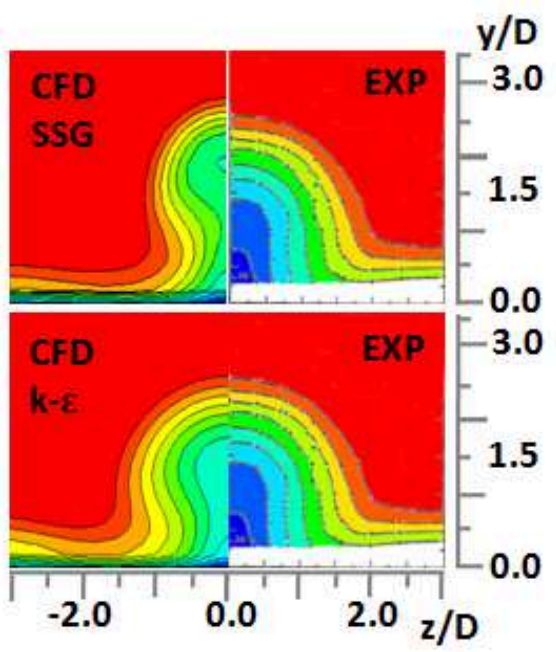

Figure 3: Normalized u-velocity on the $\mathrm{ZY}$ plane at $\mathrm{x} / \mathrm{D}=10$

Downstream Flow Structure. Figure 3 shows the comparison between the normalized u-velocity contour predicted by the RANS analyses and the experiments of Pietrzyk [6] on YZ plane at the x/D $=10$. The lower velocity region observed in Figure 3 is the subsequent of the blockage effect cause by the secondary jet into the main stream. The comparison shows that all turbulence models capable of predicting the blockage effect to some extend. However, SSG turbulence models overpredict the penetration of the secondary jet into the main stream suggesting a stroger CRVP are predicted by models causing a greater lift-off effect on the secondary jet. The phenomenon also indicated by the 
neck shape of the velocity contour as shown in Figure 3. In terms of penetration of the secondary air into the mainstream air, the best predicted result is shown by $\mathrm{k}-\varepsilon$ and $\mathrm{k}-\omega$ at nearly $1 \%$ decrepency followed by RNG and SST turbulence models.

Film Cooling Effectiveness. The descrepency between the predicted film cooling effectiveness among the turbulence models can be observed clearly in Figure 4. The contour of film cooling effectiveness shows high value at the near wall region and desipated in the main flow direction. Except for SSG and $\mathrm{k}-\varepsilon$ models, all the other models predict the seperation and reattachement of the secodnary jet near to the hole exit. The desipation of the film cooling effectiveness is highest predicted by $\mathrm{k}-\varepsilon$ and RNG followed by $\mathrm{k}-\omega$ and SSG and SST. Although trivial, it is worth to notice that the SST predicted spread of film cooling effectiveness at the lateral space of the cooling hole suggesting that vigrous interactions between the secondary jet and the mainflow are predicted. This can also explains on the wider spread of the film cooling

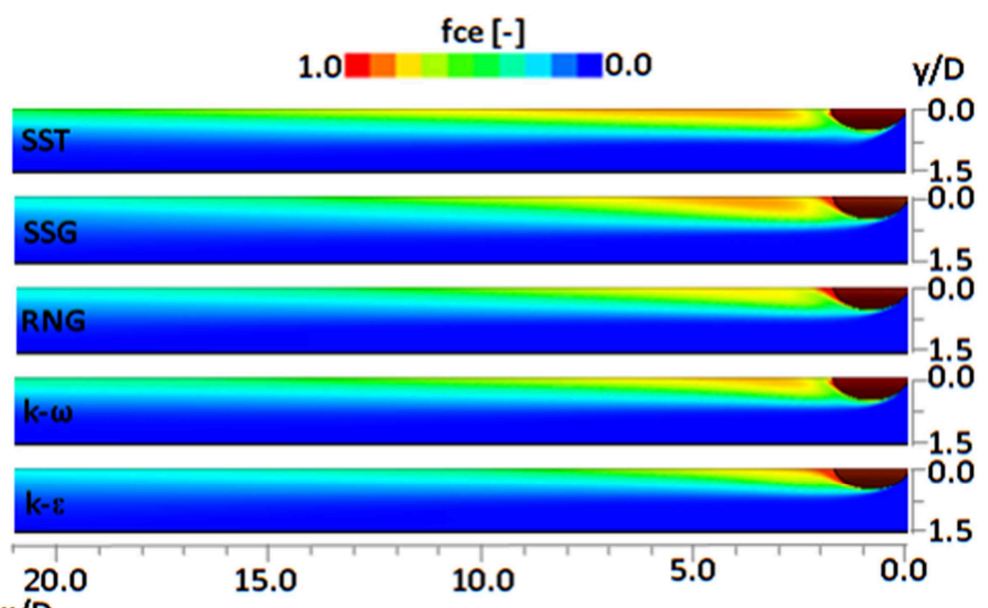
$x / D$

Figure 4: Film Cooling Effectiveness Contour

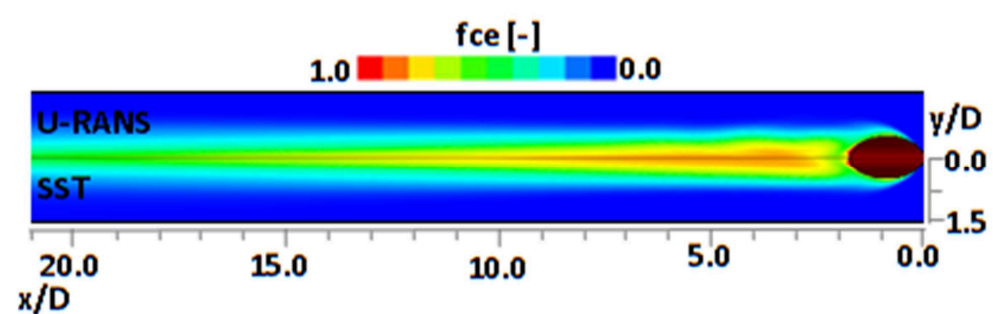

Figure 5: Comparison between Film Cooling

Effectiveness Contour of RANS and U-RANS further downstream.

U-RANS Results. Figure 5 shows the comparison of the film cooling effectiveness between RANS SST and U-RANS on XY plane at $\mathrm{z} / \mathrm{D}=0$. It can be observed that the RANS SST failed to capture the unsteadiness of the flow behavior in comparison with the U-RANS. The result of U-RANS shows a bumpy shape of the film cooling effectiveness as been shown in Figure 5. Although not presented, the difference between film cooling effectiveness predicted by steady RANS and unsteady RANS is minimal. In terms of the flow structure, significant shift can be observed at the region away from the wall involving interaction between the secondary air and the mainstream air. However, the aforementioned shift give minimal effect to the prediction of the film cooling effectiveness.

\section{Conclusion}

Comparison between the RANS turbulence model upon flat-plate film cooling have been studied numerically. Five different turbulent models have been considered; SST, SSG, RNG, k- $\omega$ and $\mathrm{k}-\varepsilon$. In addition to that, U-RANS analysis has also been carried out to provide information on the deficiency of RANS analysis. Both aerodynamics and thermal aspect of film cooling have been discussed. Although all the turbulent models capable of producing the main features of flow structure the discrepancy between them is obvious. Observation on the aerodynamics and thermal results reveals that the capability of the turbulent models to resolve the CRVP formation inside and downstream of the cooling hole is an important factor that influences the accuracy of the prediction. In addition, the comparison of the cooling effectiveness on the wall between all model simulations shown that SST and U-RANS model simulations predicted a higher cooling efficiency than other models. 


\section{Acknowledgement}

The author would like to thank both Universiti Tun Hussien Onn Malaysia (UTHM) and Ministry of Education of Malaysia (MoE) for the financial support through Research Acculturation Grant Scheme (R036).

\section{Reference}

[1] Meherwan P.B., 2002, "Gas Turbine Engineering Handbook", $2^{\text {nd }}$ edition, Gulf Professional Publishing, Houston, Texas, 800, pp. 3-23.

[2] Han, J.C., Dutta, S., and Ekkad, S, 2000, "Gas Turbine Heat Transfer and Cooling Technology," Taylor and Francis, New York, pp. 129-436.

[3] Andreopoulos, J., Rodi, W., 1984 “ Experimental Investigation of Jets in a Crossflow,” J. of Fluid Mechanics, Vol. 138, pp. 93-127.

[4] Fric, T.F., Roshko, A., 1994, "Vortical Structure in the Wake of Transverse Jet. J. of Fluid Mechanics, Vol, 279, pp. 1-47.

[5] Pietrzyk, J.R., Crawford, M.E., Bogard, D.G., 1988, "Hydrodynamic Measurements of Jets in Crossflow for Gas Turbine Film Cooling Applications", ASME Paper No. 88/GT/174.

[6] Pietrzyk, J.R., 1989, "Experimental Study of the Interaction of Dense Jets with a Crossflow for Gas Turbine Applications", PhD Thesis, University of Texas at Austin.

[7] Goldstein R.J., Eckert, E.R.G., and Burggraf, F, 1974, "Effect of Hole Geometry and Density on Three Dimensional Film Cooling," Int. J. Heat Mass Transfers, Vol. 17, pp. 595-607

[8] Ely M.J., and Jubran, B.A., 2009, "A Numerical Evaluation On The Effect Of Sister Holes On Film Cooling Effectiveness And The Surrounding Flow Field”, J. Heat Mass Transfers, Vol. 45, pp. 1435-1446.

[9] Ekkad, S.V., Heidmann, J., Dhungel, A., Lu, Y., and Wynn P., 2009,"Film Cooling From a Row of Holes Supplemented with Antivortex Holes,"ASME J. Turbomachinery, Vol. 131, pp. 021007-10.

[10] Kamil, A., Funazaki, K., Onodera, H., and Ideta, T., 2012, "Experimental Investigations on Aero-Thermal Interaction of Film Cooling Air Ejected from Multiple Holes: Shallow Hole Angle, ’Proceeding of ASME Turbo Expo 2012, Denmark, pp. GT2012-68215. 